\title{
Some Field Model Validation Studies
}

\author{
G. COX and S. KUMAR
}

Fire Research Station

Borehamwood, Herts WD6 2BL, United Kingdom

\author{
N. C. MARKATOS \\ Thames Polytechnic \\ London SE18 6PF, United Kingdom
}

\section{ABSTRACT}

The three dimensional time-dependent field model known as JASMINE has been applied to several experimental fire configurations for validation purposes. Comparisons of predictions with non-spreading experimental fires conducted in a forced ventilated fire test cell $(6 \mathrm{~m} \times 4 \mathrm{~m} \times 4.5 \mathrm{~m})$, closed six-bed hospital ward $(7.3 \mathrm{~m} \times 7.9 \mathrm{~m} \times 2.7 \mathrm{~m})$ and a railway tunnel, both forced and naturally ventilated (390 m $55 \mathrm{~m} \times 4 \mathrm{~m}$ ) are summarised in this paper. The agreement is shown to be quite satisfactory except in the immediate vicinity of the fire source. It is suggested that the model may now be used with some caution to study smoke movement problems, however, improvements to the turbulence - chemistry interaction at the source will be required before the spreading fire can be reliably predicted.

Keywords: Mathematical Model, Fire, Smoke, Validation, Tunnel, Hospital.

\section{INTRODUCTION}

Mathematical fire models will only enjoy widespread acceptance when and if sufficient validation can be demonstrated for them. The prospective user must have enough confidence in a model to be able to apply it to situations, new building types for example, in which there is no practical experience of fire behaviour. There is limited value in developing an accurate model that can only be applied to one size of compaxtment for example. It is the generality of the field modelling approach to the problem that should offer significant advantages in terms of the transportability of models to very different compartment types. It is not the intention of this paper to describe in detail the mathematical field model being employed in these studies. The reader will find these elsewhere and in particular in refs 1 to 3 .

Suffice it to say here that the so-called field modelling approach is essentially a first-principles approach, solving the classical equations of motion for the gas at descrete points in space and time, retaining as much rigour as is practically possible. The need to treat turbulent mixing by a turbulence model, and the use of numerical methods to solve the equations, are the principle points of departure from full rigour. However these departures are not unique to fire research problems and have evolved in many other areas of application of computational fluid dynamics to engineering problems. Although not without controversy, there is a growing body of evidence to support its successful practical application. 
The object of this contribution is to summarise some recent validation work with the Fire Research Station's field model krown as JASMINE (for Analysis of Smoke Movement in Enclosures) in three distinctly different situations. Two of these concern rooms of similar size, in one case with no significant ventilation openings and in the other with forced ventilation. The third case concerns a railway tumel both naturally and forced ventilated and with a slope from one end to the other.

These represent the most recent phase of a progressive validation and development study starting with its two-dimensional, non reacting steady-state predecessor through studies of the validity of traditional scaling relationships to the current three-dimensional, time-dependent version including chemical reaction. Some of these studies have been described in references 1 to 5 .

\section{THEORETICAL FOUNDATION OF THE MODEL}

Field models are based on the solution of the partial differential equation set describing the conservation of mass, momentum, heat, and species concentration etc., and therefore represent a first principles approach to the problem.

In fire problems the flow is generally dominated by buoyancy. This gives rise to large scale turbulent motion which controls the rate of diffusion of mass, momentum and the mixing of fuel volatiles with air. The rate of reaction of fuel and air is also controlled by this relatively slow turbulent mixing process rather than the fastex chemical kinetics. The non-uniform buoyancy forces not only drive the flow but also increase turbulent mixing in the rising plume and inhibit it in hot stratified layers.

These characteristic features of fire have been incorporated in JASMINE. In summary, the model solves simultaneous non-linear partial differential equations for the nine dependent variables describing the system, ie, the three velocity components $(u, v, w)$, the pressure $(p)$, the enthalpy $(h)$, the mixture and mass fractions of the fuel $\left(f_{,} \mathrm{m}_{\mathrm{fu}}\right)$, the turbulent kinetic energy $(k)$ and its disipation rate $(\epsilon)$.

All these dependent variables, with the exception of pressure, appear as the subjects of differential equations of the general form:

$$
\frac{\partial}{\partial t}(\rho \phi)+\operatorname{div}\left(\overrightarrow{\rho u} \phi+\vec{J}_{\phi}\right)=S_{\phi}
$$

where $\phi$ stands for a general fluid property and $\rho, \vec{u}, \vec{J}, S_{\phi}$ are density, velocity vector, diffusive-flux vector and source rate per unit volume, respectively. The diffusive flux $\vec{J}_{\phi}$ is given by:

$\vec{J}_{\phi}=-\Gamma_{\phi} \operatorname{grad} \phi$

where $\Gamma_{\phi}$ denotes the 'effective exchange coefficient of $\phi$ ' determinea from the turbulence parameters $\mathrm{k}$ and $\epsilon$. The pressure variable is associated with the continuity equation:

$\frac{\partial \rho}{\partial t}+\operatorname{div}(\rho \vec{u})=0$

The source term of the transport equation for $m_{f u}$ is calculated ${ }_{8}$ ising Magnussen and Hjertager's extension of spalding 's eddy-break-up concept. The values of $\Gamma_{\phi}$ and $S_{\phi}$ for each $\phi$ and details of the formulation of the finite difference equations from Eq (1) togethex with features of the numerical algorithm are given in refs 1 to 3 . A six-flux radiation model is incorporated in JASMINE but in what follows, effects of radiant heat transfer have been ignored. Some calculations of the radiant contribution have been reported in 
ref 4 . The boundary conditions have been discussed in refs $1-3$.

\section{EXPERIMENTAL CONFIGURATIONS USED FOR VALIDATION STUDIES}

\section{(i) Lawrence Livermore National Laboratory fire test cell.}

The fire test cell at the Lawrence Livermore National Laboratory (LLNL), is $4 \mathrm{~m}$ x $6 \mathrm{~m}$ in plan and $4.5 \mathrm{~m}$ high, represented numerically by $12 \times 13 \times 14$ grid nodes. A rectangular duct $0.65 \mathrm{~m}$ square centred $3.6 \mathrm{~m}$ above the floor provides forced extraction by control of an axial fan. Air inlet is at low level through slots in a cylindrical duct close to one face of the compartment. This has been approximated in the model by one slit $0.12 \mathrm{~m}$ high, $2 \mathrm{~m}$ long, $0.1 \mathrm{~m}$ aboye the floor. The particular fire examined here (designated Mod 8 by Alvares et al ${ }^{9}$ ) was produced by burning a spray of isopropyl alcohol formed from an opposed jet nozzle located at the centre of a steel pan of diameter $0.91 \mathrm{~m}$. The fuel is quickly evaporated and burnt before it contacts the pan surface. The resulting fire is very similar to a natural pool fire.

The fuel injection rate was $13.1 \mathrm{gm} / \mathrm{s}$ adjusted to give a heat release rate of $400 \mathrm{~kW}$, assuming efficient combustion. The ventilation extraction rate, which was adjusted to 500 litres/s of air prior to ignition, had dropped to 400 litres/s just before test completion (20 minutes from ignition). At this time, experimental conditions were assumed to have reached a quasi-steady state for which the predictions were made with a global heat transfer coefficient of 20 $\mathrm{W} / \mathrm{m}^{2}{ }^{\circ} \mathrm{K}$. Complete oxidation of the fuel was assumed in a one-step combustion model for this and the following studies.

\section{(ii)}

\section{Zwenberg tunnel}

The experiments are those conducted in the disused railway tunnel at Zwenberg, Austria and described by Fiezlmayer ${ }^{10}$. The tunnel is $390 \mathrm{~m}$ long and $5 \mathrm{~m}$ across with a false ceiling $4 \mathrm{~m}$ above the floor. There is a $2.18 \%$ gradient from the south to the north portal. Since the fire was symmetrically situated in the experiment, the calculation domain occupied one half of the tunnel from the symmetry plane (through the axis of symmetry) down the centre of the tunnel across to the east wall, and contained a total of 1566 grid nodes distributed in a nonuniform manner with six nodes across the tunnel half-width, 9 nodes vertically and 29 along the length. The tunnel was sealed at the south portal and an injection fan inserted in the end wall. In the test cases considered here, the fan was either switched off (natural ventilation from the open north portal) or produced a forced air flow in the traffic space of $2 \mathrm{~m} / \mathrm{s}$ and $4 \mathrm{~m} / \mathrm{s}$ (cases of pure longitudinal ventilation). All three ventilation cases involved fires of 200 litres of petroleum fuel burnt in a $2.6 \mathrm{~m}$ square tray. The fire source in each case was situated $108 \mathrm{~m}$ from the south portal. The fuel mass loss rates, for the three ventilation conditions were calculated using the data of Yumoto 11 to allow for the increase of linear regression rate with increased air flow rate. The effect of the resolved components of the gravitational acceleration on the vertical and 'along the slope' directions were included in the formulation.

Steady state predictions were compared with the experimental data towards the end of the fire. Hexane was considered as an idealisation for petrol.

The heat losses to the walls were calculated using a heat transfer coefficient varying linearly between $5 \mathrm{~W} / \mathrm{m}^{2}{ }^{\circ} \mathrm{K}$ and $40 \mathrm{~W} / \mathrm{m}^{2}{ }^{\circ} \mathrm{K}$ with gas temperature as sugested by the Harvard zone model ${ }^{12}$. 


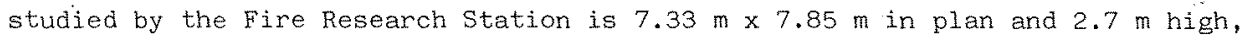
discretised into $14 \times 13 \times 11$ grid nodes for its numerical representation. Six $1 \mathrm{~kW}$ radiators situated close to the north wall have been represented by one floorstanding $6 \mathrm{~kW}$ heater, $7.85 \mathrm{~m}$ in width and $0.5 \mathrm{~m}$ in height. The fire source was assumed to occupy a fixed area of $0.45 \mathrm{~m} \times 0.5 \mathrm{~m}$ of polyurethane (PU) foam mattress, situated next to the pillow $0.25 \mathrm{~m}$ away from the east wall. The actual fuel was far more complex than just PU foam, comprising a small wood crib for ignition and including cotton, nylon and polyester bedding materials. However for modelling purposes, PU foam, being the major component, was considered to be a reasonable approximation for the fuel.

Prior to the start of the experimental fire, the steady-state natural convection conditions were established by leaving the heaters on for several hours. The bed was ignited by a small wood crib. Three distinct phases of mass loss were evident from load cell measurements. The first phase lasted for about 3 minutes where the wood crib was mainly involved and the heat output was estimated at approximately $5 \mathrm{kw}$, assuming a combustion efficiency of 0.65 . In the second phase, up to 7 minutes from ignition, the PU foam mattress was more actively involved with the heat output rising to about $20 \mathrm{~kW}$. In the third phase the pillow also became involved and the flames lengthened to around one metre and heat release rose to approximately $80 \mathrm{kw}$ until about 12 minutes from ignition when the test was abandoned. Transient calculations were performed by assuming that these three phases could be represented by three stepped levels of mass release following a steady state calculation for the prefire conditions.

The heat losses to the walls were calculated as in the Zwenberg tunnel case.

\section{RESULTS}

\section{(i) Lawrence Livermore National Laboratory fire test call.}

One of the difficulties of validating this type of model is the considerable quantity of detailed information predicted and the very difficult task of obtaining enough experimental data to examine the details. Even in such a thoroughly instrumented experimental rig as the LLNL test cell it is only possible to compare predictions and experiments at comparatively few points.

Eredictions of velocity vectors are shown on two orthogonal planes in a perspective view of the cell viewed from the east in Fig 1 . The two planes are the horizontal one through the air inlet slot and the vertical one through the centre of the fire tray and extract duct (hereinafter known as the central plane). The processes of air entrainment into the fire, buoyant vertical acceleration of the plume, formation of a ceiling jet and the establishment of recirculation in the cell are clearly evident. Examination of vectors, on vertical planes parallel to that shown here, clearly demonstrates a leaning of the fire towards the south wall. A sample streamline is illustrated in Fig 1, starting at the inlet slot and rising three times before finally leaving at the extract duct.

The predictions of temperature, mass fractions of fuel, oxygen and product on the vertical plane through the centre of fire tray and exit duct are shown in Fig 2. The oxygen mass fraction above about $0.5 \mathrm{~m}$ from the floor is uniform at between $10 \%$ and $11 \%$ and product $\left(3 \mathrm{CO}_{2}+4 \mathrm{H}_{2} \quad 0\right)$ mass fraction at between $16 \%$ and $17 \%$. The unburnt fuel mass fraction is everywhere very low except at the source. Gas temperatures in the compartment show a steady increase from floor to ceiling in good agreement with the experiment. Over and within the fire source itself temperatures decay in the expected way but peak values are low compared with experimental determinations (around $1250 \mathrm{~K}$ ). This may be the result of either the simplicity of the combustion model used or even the coarseness of the grid in the vicinity of the source (approximately $0.25 \mathrm{~m}$ cube). It is well known that 


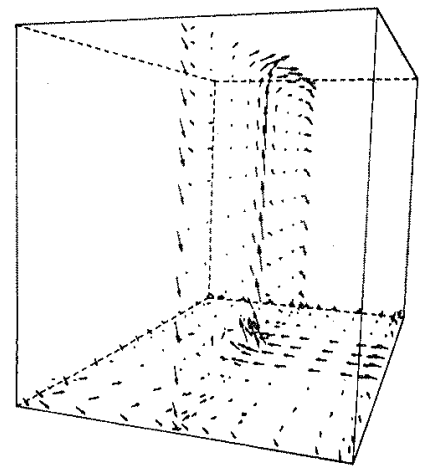

(a) Velocity vectors on two orthogonal planes

FIG 1 Perspective view from the east

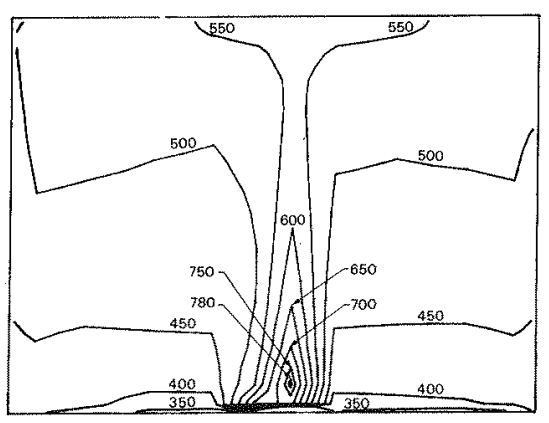

Absolute temperature contours (K)

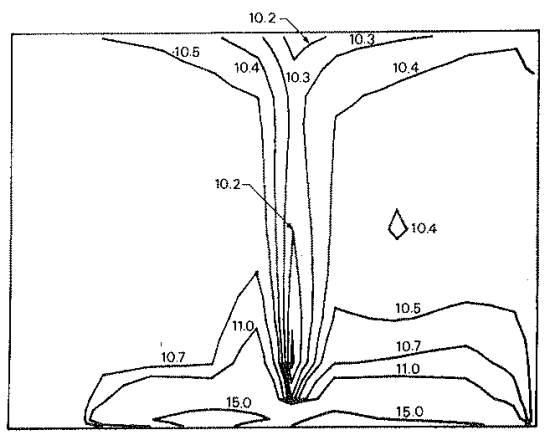

Percentage mass fraction of oxygen

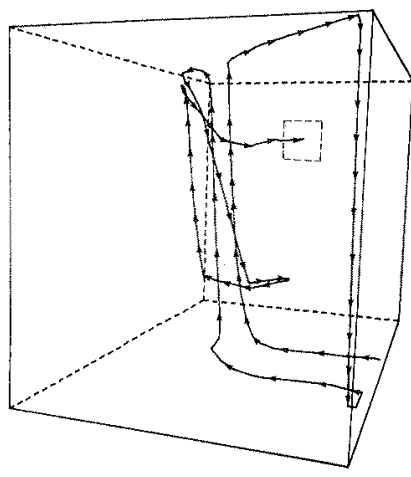

(b) Sample streamline starting at inlet slot

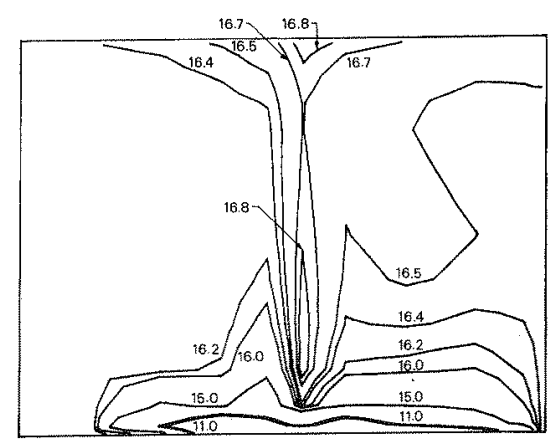

Percentage mass fraction of product

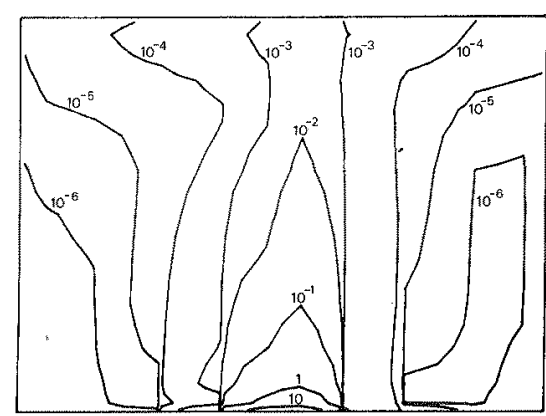

Percentage mass fraction of fuel

FIG 2 Gas property contours on central plane 


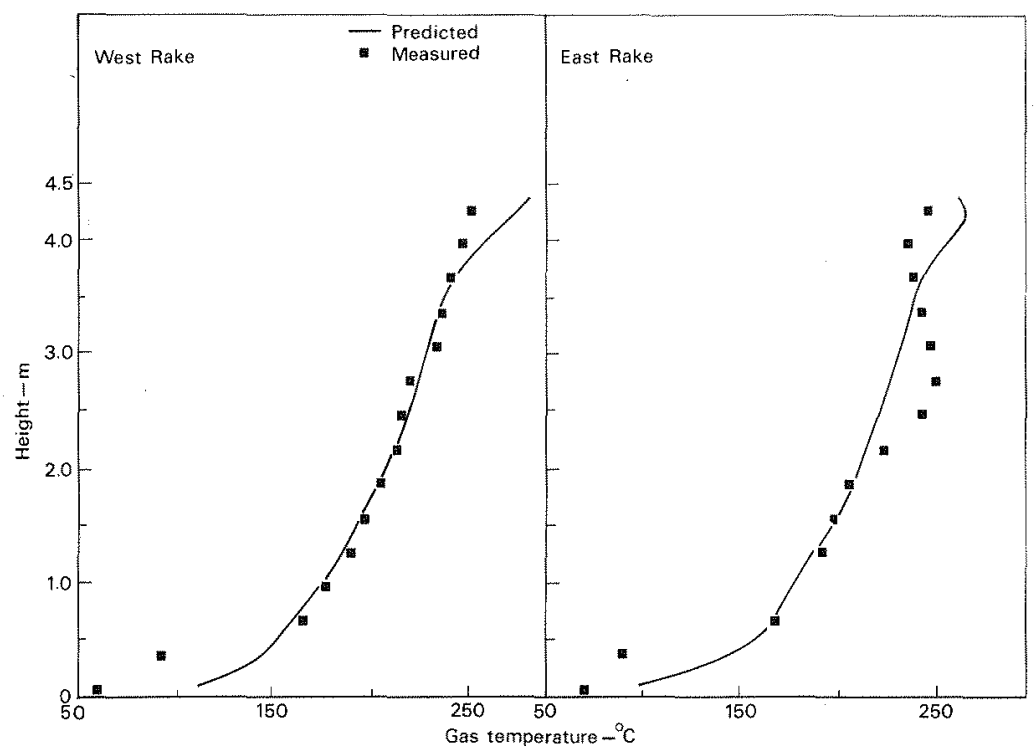

Gas temperature with height at two thermocouple rakes

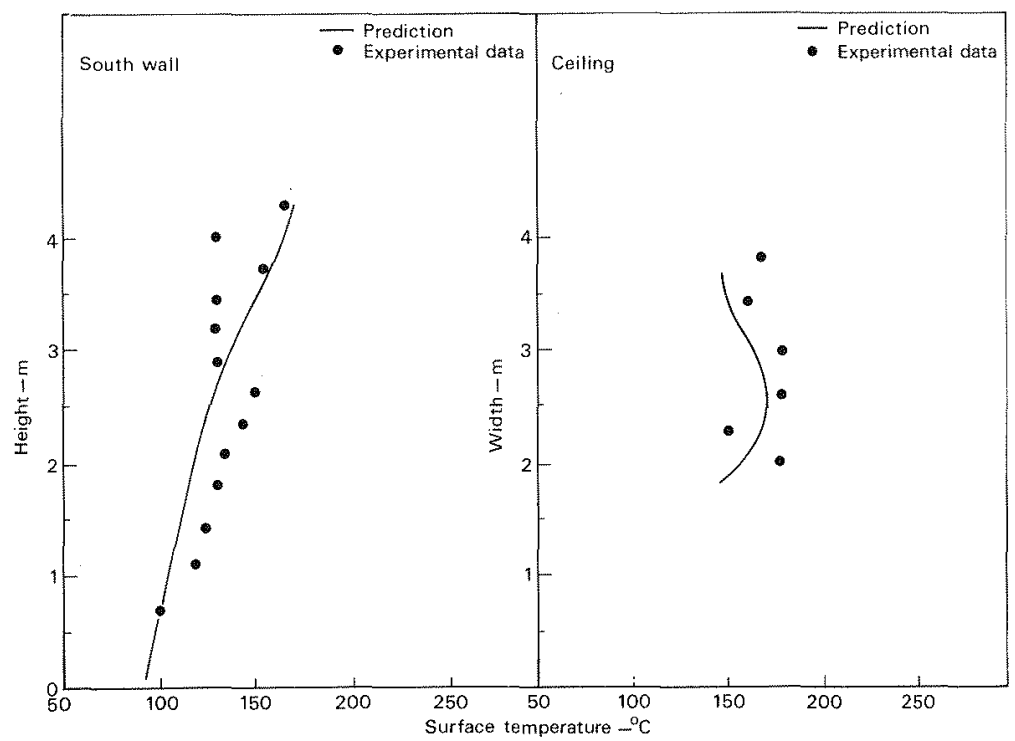

Surface temperature with height on south wall and ceiling

FIG 3 Temperature profiles in the LLNL test cell 
fires exhibit strong combustion intermittency ${ }^{13}$ and current research is directed towards more realistic modelling of the turbulence-chemistry interactions

Temperatures measured at two vertical thermocouple rakes situated $1.5 \mathrm{~m}$ either side of the fire tray on the central plane, and each comprising 15 thermocouples are compared with predictions in Fig 3. Wall surface temperature predictions are also compared in Fig 3 with measurements on the vertical centreline of the south wall and on the continuation of this line onto the ceiling to its centre (over the fire tray). Overall agreement can be seen to be reasonably good, although gas temperatures close to the floor and ceiling are predicted somewhat high.

Overall properties and some point determinations are compared in Table $I$. In general, agreement is seen to be excellent. The difference beween computed inlet and outlet mass flow rates corresponds to the 13 grams/s injection rate of fuel. The gas composition predictions are somewhat disappointing compared with the success of the thermal predictions. This again is likely to be due to the source prescription problem mentioned earlier.

The predicted pressure at the level of the extract duct differs markedly from the measurement. The reason for this is not clear but is likely to be caused by the contribution of dynamic pressure to the measurement. Lack of space here precludes further discussion but more details will be found in Ref 3 .

TABLE I. Comparison of predictions and measurements of integral properties and some point determinations

\begin{tabular}{|c|c|c|}
\hline Property & Predicted & Measured \\
\hline Mass outflow rate $(\mathrm{kg} / \mathrm{s})$ & 0.269 & 0.30 \\
\hline Mass inflow rate $(\mathrm{kg} / \mathrm{s})$ & 0.257 & 0.24 \\
\hline Exit gas temperature $\left({ }^{\circ} \mathrm{C}\right)$ & 249 & 275 \\
\hline Exit heat flow (kW) & 66 & 68 \\
\hline Exit pressure above ambient $(\mathrm{Pa})$ & 14.3 & -5 \\
\hline Exit $\mathrm{O}_{2}$ concentration $(\%)$ (dried gas) & 10.4 & 14 \\
\hline Exit $\mathrm{O}_{2}$ concentration (\%) (dried gas) & 7.5 & 5.5 \\
\hline Total heat loss to boundaries ( $\mathrm{kW}$ ) & 334 & 332 \\
\hline
\end{tabular}



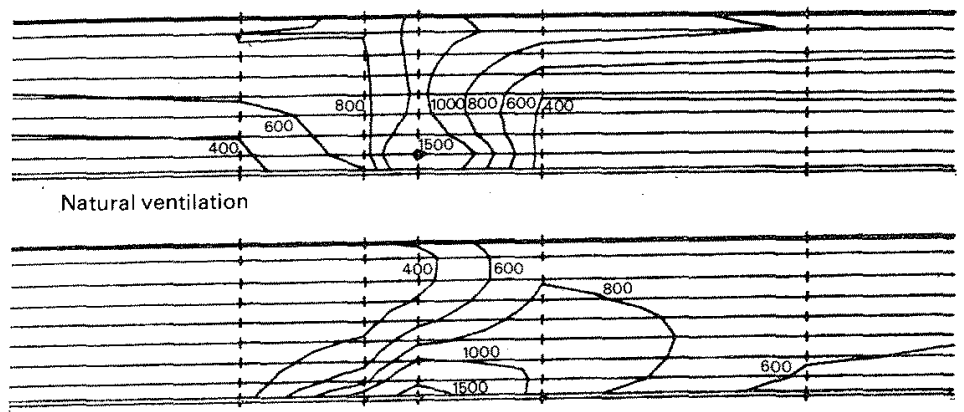

Pure longitudinal ventilation of $2 \mathrm{~ms}^{-1}$

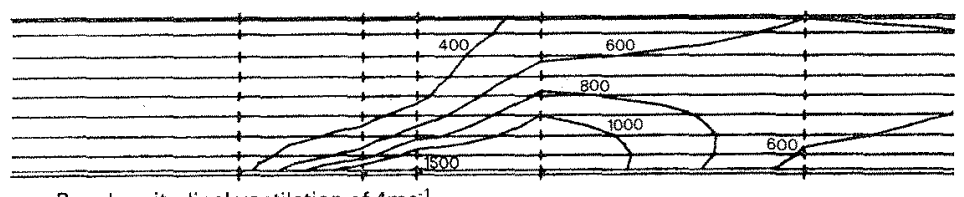

Pure longitudinal ventilation of $4 \mathrm{~ms}^{-1}$

(a) Temperature contours (K)

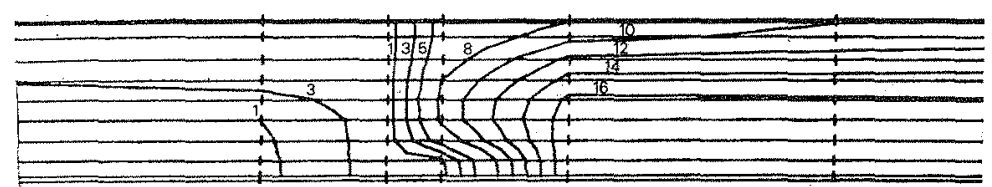

Natural ventilation

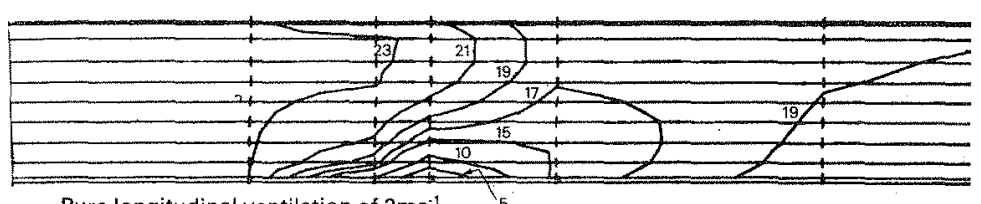

Pure longitudinal ventilation of $2 \mathrm{~ms}^{-1}$

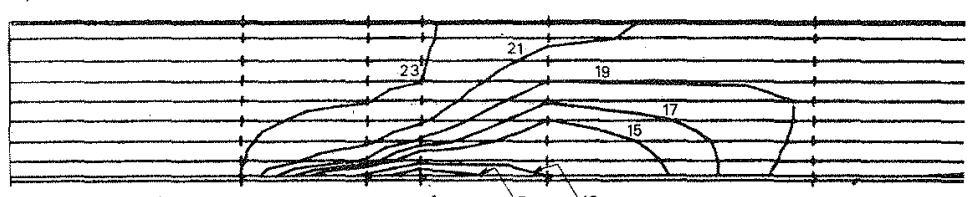

Pure longitudinal ventilation of $4 \mathrm{~ms}^{-1}$

(b) Percentage oxygen mass fraction contours

FIG 4 Predicted gas property contours on the central plane of Zwenberg Tunnel $123 \mathrm{~m}$ long magnified section around fire) 
TABLE II: Comparison of Measured and Predicted Gas Properties for the Case of Pure Longitudinal Ventilation of $4 \mathrm{~m} / \mathrm{s}$

\begin{tabular}{|c|c|c|c|c|c|c|c|c|c|c|c|c|c|c|c|}
\hline \multirow{2}{*}{\multicolumn{2}{|c|}{$\begin{array}{l}\text { Measurement } \\
\text { Station: } \\
\text { Gas Property }\end{array}$}} & \multicolumn{2}{|c|}{1} & \multicolumn{2}{|c|}{2} & \multicolumn{2}{|c|}{3} & \multicolumn{2}{|c|}{4} & \multicolumn{2}{|c|}{5} & \multicolumn{2}{|c|}{6} & \multicolumn{2}{|c|}{7} \\
\hline & & Pred & Meas & Pred & Meas & Pred & Meas & Pred & Meas & Pred & Meas & Pred & Meas & Pred & Meas \\
\hline \multirow{3}{*}{$\begin{array}{l}\text { Temperature } \\
\left({ }^{\circ} \mathrm{C}\right)\end{array}$} & $\mathrm{H}$ & 131 & 88 & 198 & 220 & 224 & 227 & 394 & 312 & 12 & 176 & 10 & 12 & 10 & 12 \\
\hline & $M$ & 109 & 84 & 178 & 136 & 183 & 178 & 426 & 458 & 93 & - & 10 & 12 & 10 & 12 \\
\hline & L & 86 & 80 & 140 & 120 & 152 & 120 & 341 & 312 & 638 & & 10 & 12 & 10 & 12 \\
\hline \multirow{3}{*}{$\begin{array}{l}\text { Volumetric } \\
\text { Concentration } \\
\text { (\%) of } \mathrm{O}_{2} \\
\text { (dried gas) }\end{array}$} & $\mathrm{H}$ & 19.3 & - & $\begin{array}{l}19.1- \\
19.2\end{array}$ & 19.3 & $\begin{array}{l}19.0- \\
19.1\end{array}$ & - & $\left|\begin{array}{l}19.7- \\
17.7\end{array}\right|$ & - & - & - & - & - & - & - \\
\hline & $M$ & 19.3 & 19.5 & $\begin{array}{l}19.1- \\
19.4\end{array}$ & $\begin{array}{l}19.3- \\
19.6\end{array}$ & $\begin{array}{l}19.1- \\
19.4\end{array}$ & $\begin{array}{l}19.2- \\
19.7\end{array}$ & $\begin{array}{l}20.0- \\
17.4\end{array}$ & - & - & - & - & - & - & - \\
\hline & L & 19.3 & 19.5 & $\begin{array}{l}19.2- \\
19.5\end{array}$ & 19.6 & $\begin{array}{l}19.3- \\
19.6\end{array}$ & $\begin{array}{l}19.7- \\
20.1\end{array}$ & $\begin{array}{l}20.3- \\
18.2\end{array}$ & - & - & - & - & - & - & - \\
\hline \multirow{3}{*}{$\begin{array}{l}\text { Volumetric } \\
\text { Concentration } \\
\text { (\%) of } \mathrm{CO}_{2} \\
\text { (dried gas) }\end{array}$} & $\mathrm{H}$ & 1.1 & - & 1.2 & 1.4 & $1.3-$ & - & $\begin{array}{l}0.8- \\
2.1\end{array}$ & 1.1 & - & - & - & - & - & - \\
\hline & $M$ & 1.1 & 1.0 & $\begin{array}{l}1.2- \\
1.0\end{array}$ & $\begin{array}{l}1.1- \\
0.9\end{array}$ & $\begin{array}{l}1.3^{-} \\
1.0\end{array}$ & $\begin{array}{l}1.3^{-} \\
0.8\end{array}$ & $\begin{array}{l}0.6- \\
2.4\end{array}$ & $\begin{array}{l}2.0- \\
5.8\end{array}$ & - & - & - & - & - & - \\
\hline & L & 1.1 & 1.0 & $\begin{array}{l}1.2- \\
0.9\end{array}$ & 0.9 & $\begin{array}{l}1.1- \\
0.9\end{array}$ & $\begin{array}{l}1.0^{-} \\
0.8\end{array}$ & $\begin{array}{l}0.4- \\
1.9\end{array}$ & $\begin{array}{l}1.0- \\
2.3\end{array}$ & - & - & - & - & - & - \\
\hline \multirow{3}{*}{$\begin{array}{l}\text { Volumetric } \\
\text { Concentration } \\
\text { (ppm) of fuel }\end{array}$} & $\mathrm{H}$ & $<1$ & - & $<1$ & - & 3 & - & $1-60$ & 250 & - & - & - & - & - & - \\
\hline & M & $<1$ & - & $<1$ & - & 4 & - & $1-170$ & $\begin{array}{l}240- \\
1750\end{array}$ & - & - & - & - & - & - \\
\hline & $L$ & $<1$ & - & $<1$ & - & 2 & - & $1-250$ & $\begin{array}{l}100- \\
1100\end{array}$ & - & - & - & - & - & - \\
\hline
\end{tabular}




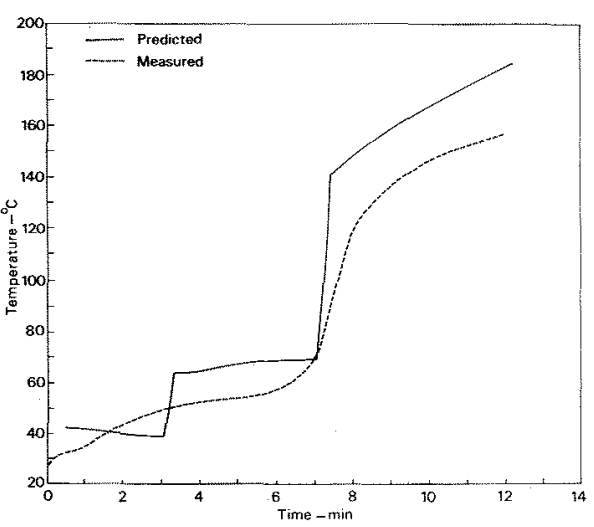

(a) Evolution of gas temperature above fire

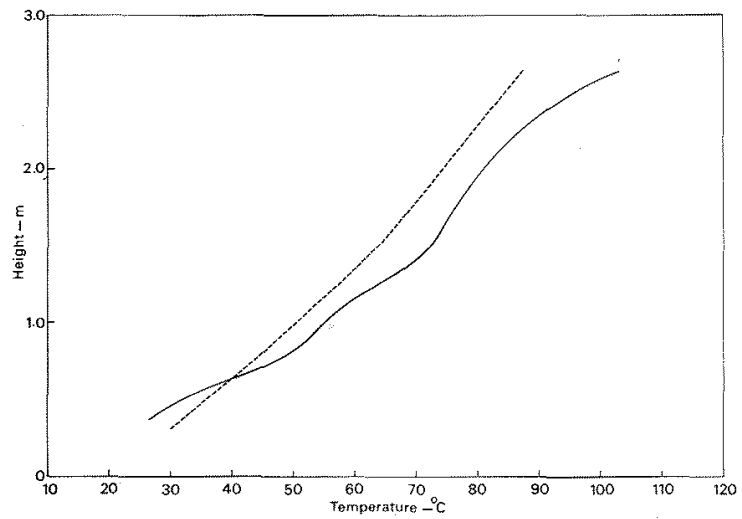

(c) Gas temperature profile near bed at $12 \mathrm{~min}$

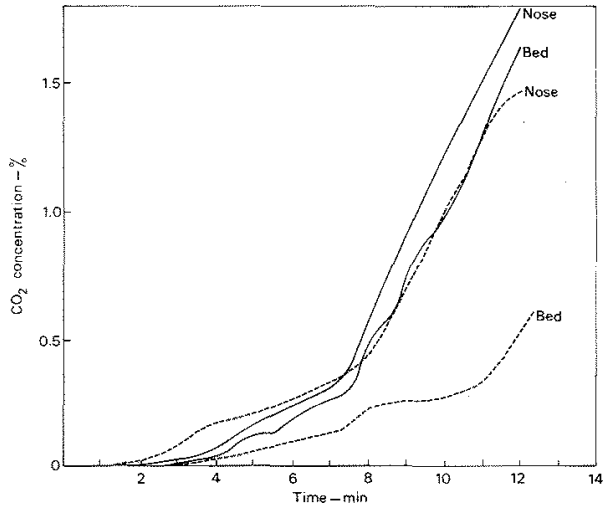

(b) $\mathrm{CO}_{2}$ concentrations at nose and bed heights

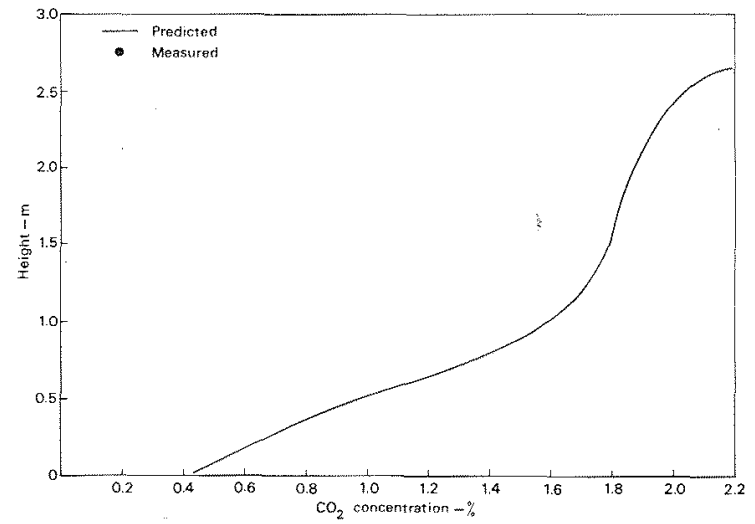

(d) $\mathrm{CO}_{2}$ profile near bed at $12 \mathrm{~min}$

FIG 5 Gas temperature and $\mathrm{CO}_{2}$ concentration in six-bed hospital ward 
Fig 4 shows the detailed temperature and oxygen mass fraction contours in. an enlarged portion of the tunnel around the source.

Detailed comparisons between the predictions and measurements for one test case $(4 \mathrm{~m} / \mathrm{s})$ are shown in Table II. It is clear from these tabulated results and from those for naturally ventilated and lower forced ventilated situations (not shown because of space limitations) that the agreement throughout is reasonably good except very close to the fire. The discrepancy between the predictions and measurements immediately above the fire is due to radiant heat transfer (not included in the predictions) whereas that within the flames due to the coarse grid and the simple combustion model used, as mentioned earlier.

It is interesting to compare estimates of flame angles from the model with Thomas's empirical correlation 16 . Assuming $600^{\circ} \mathrm{K}$ or $21 \%$ oxygen mass fraction as the extent of flame front, the flame angles agree remarkably well. At $2 \mathrm{~m} / \mathrm{s}$ Thomas's correlation gives 58 degrees with respect to the vertical whilst the model gives 61 degrees and at $4 \mathrm{~m} / \mathrm{s}$ both calculations give 68 degrees. More details of this study will be found in Ref 6 .

\section{(iii) Six bed hospital ward}

Buoyancy driven flow in a sealed cavity is one of the most challenging problems in the field of computational fluid dynamics ${ }^{2}$. Therefore this particular test case is one of considerable interest.

Since the previous two test cases have already demonstrated a wide variety of predictive capabilities of this type of mathematical model, only direct comparison of the predicted transient results with the measurements is shown for this case. In Fig $5 a$ and $b$ the evolution of predicted and measured gas temperatures and $\mathrm{CO}_{2}$ concentration is shown at some selected locations. The temperature $75 \mathrm{~mm}$ below the ceiling, directly above the fire, has been chosen to demonstrate a worst case. The three phases of fire development can be clearly seen particularly in the predictions. At similar heights, further from the source, agreement is better as was experienced in the previous test cases.

The $\mathrm{CO}_{2}$ concentrations shown are for 'nose' and 'bed' heights close to the bed and respectively $1.5 \mathrm{~m}$ and $0.9 \mathrm{~m}$ above the floor. At nose height the predictions are in reasonable agreement but at bed height they are considerably in error. Although detailed gas concentration profiles were not measured it appears that the model has overpredicted the extent of species diffusion in the vertical direction ( $F i g$ C), whilst the corresponding temperature profiles do agree reasonably well (Fig 5d). With the complex solid fuel involved in the experiment, questions remain as to whether this difficulty occurs as a result of the oversimplified prescription of the source or again the problems of turbulencechemistry interaction and coarseness of grid at the source. These possibilities are currently under investigation.

\section{CONCLUSTONS}

It has not been possible, in the space available, to give full details of each validation study but more on the LLNL and Zwenberg tumel comparisons wil1 be found in Refs 3 and 6 . However it can be concluded that al though not perfect, and by no means exhaustively validated, JASNINE does appear to offer a reliable tool for the prediction of detailed thermal properties of non-spreading fire problems where radiant heat transfer is relatively less important than convection. Developments concentrate now more on improving details, at least for smoke movement problems, rather than the overall solution concept. 
Several aspects still need improvement, particularly the treatment of the turbulence-chemistry interaction, if more accurate gas concentration predictions are to be made. Furthermore a more universal treatment for the calculation of heat losses to the boundaries is required to maintain the generality of solution technique aspired to by the field modelling approach. Clearly a more realistic treatment of the source will be necessary if the model is to be used to predict surface flame spread and mass burning rates.

\section{ACKNOWLEDGEMENTS}

The authors wish to acknowledge the contribution of Nicole Hoffmann to the hospital ward study. To conduct this work she was supported by a grant from the Department of Health and Social Security.

The work on tunnels was conducted under a contract to the Department of Transport. The paper forms part of the work of the Fire Research Station, Building Research Establishment, Department of the Environment, UK. It is contributed by permission of the Directors of the Building Research Establishment and the Transport and Road Research Laboratory.

\section{REFERENCES}

1. N C Markatos, M R Malin and G Cox : J Heat Mass Transfer 25, 63 (1982).

2. N C Markatos and G Cox : Physiochemical Hydrodynamics 5, 53 (1984).

3. G Cox and S Kumar : The Mathematical Modelling of Fire in Force Ventilated Enclosures, 18th DOE Nuclear Airborne Waste Management and Air Cleaning Conference, Baltimore, August 1984.

4. $\mathrm{N} \mathrm{C} \mathrm{Markatos} \mathrm{and} \mathrm{K} \mathrm{A} \mathrm{Pericleous} \mathrm{:} \mathrm{An} \mathrm{investigation} \mathrm{of} \mathrm{Three} \mathrm{Dimensional}$ Fires in Enclosures, in Fiŕe Dynamics and Heat Transfer ed $J$ Quintiere, ASME, 1983, p115.

5. S Kumar and G. Cox. 'The Application of a Numerical Field Model of Smoke Movement to the Physical Scaling of Compartment Fires' in Numerical Methods in Thermal Problems, ed $R$ W Lewis, $J A$ Johnson and $W R$ Smith. Pineridge Press 1983, p837.

6. S Kumar and G Cox : Mathematical Modelling of Fire in Road Tunnels. Fifth International Conference on the Aerodynamics and Ventilation of Vehicle Tunnels, Lille, 1985.

7. B F Magnussen and B H Hjertager : Sixteenth Symposium (International) on Combustion. The Combustion Institute, 1976, p719.

8. D B Spalding : Thirteenth Symposium (International) on Combustion. The Combustion Institute, 1971, p649.

9. N J Alvares, K L Foote and P J Pagni : Comb Sci and Technol. 39, 55 (1984).

10. A H Fiezlmayer : Brandversuche in einem Tunnel, Bundesministerium fur Bauten und Technik, Heft 50, Vienna, 1976.

11. T Yumoto : J Japan Society for Fire Safety Eng. 10, No.3 (1971).

12. H E Mitler : 'The physical basis for the Harvard Computer Code'. Home Fire Project Tech Rept No.34, Harvard University (1978).

13. G Cox and R Chitty. Fire and Materials. 6, 127 (1982). 
14. N L Crauford, S K Liew and J B Moss : Experimental and Numerical Simulation of a Buoyant Fire. Submitted to Combustion and Flame.

15. D B Spalding : Physiochemical Hydrodynamics. 4, 323 (1983).

16. P H Thomas : Ninth Symposjum (Intemational) on Combustion p844 (1963).

17. I P Jones and C P Thompson : Numerical Solutions for a Comparison Problem on Natural Convection in an Enclosed Cavity. UKAEA Harwe11. Report No. AERE-R.9955 (1981). 
